\title{
Is gentrification all bad? Positive association between gentrification and individual's perceived neighborhood collective efficacy in Montreal, Canada
}

\author{
Madeleine Steinmetz-Wood ${ }^{1 *}$, Rania Wasfi²,3, George Parker ${ }^{4}$, Lisa Bornstein ${ }^{5}$, Jean Caron ${ }^{6}$ and Yan Kestens ${ }^{2,3}$
}

\begin{abstract}
Background: Collective efficacy has been associated with many health benefits at the neighborhood level. Therefore, understanding why some communities have greater collective efficacy than others is important from a public health perspective. This study examined the relationship between gentrification and collective efficacy, in Montreal Canada.

Methods: A gentrification index was created using tract level median household income, proportion of the population with a bachelor's degree, average rent, proportion of the population with low income, and proportion of the population aged 30-44. Multilevel linear regression analyses were conducted to measure the association between gentrification and individual level collective efficacy.

Results: Gentrification was positively associated with collective efficacy. Gentrifiers (individuals moving into gentrifying neighborhoods) had higher collective efficacy than individuals that lived in a neighborhood that did not gentrify. Perceptions of collective efficacy of the original residents of gentrifying neighborhoods were not significantly different from the perceptions of neighborhood collective efficacy of gentrifiers.

Conclusions: Our results indicate that gentrification was positively associated with perceived collective efficacy. This implies that gentrification could have beneficial health effects for individuals living in gentrifying neighborhoods.
\end{abstract}

Keywords: Gentrification, Collective efficacy, Epidemiological catchment area, Health

\section{Background}

Collective efficacy is a form of social capital that can be defined as the consolidation of neighborhood social cohesion and informal social control. Whereby, social cohesion embodies the concepts of mutual support and trust, and informal social control refers to the collective capacity of community members to coordinate their members to achieve collective goals according to a set of principles $[1,2]$. At the community level, collective efficacy is hypothesized to influence health by means of

\footnotetext{
*Correspondence: madeleine.steinmetz-wood@mail.mcgill.ca

1 Department of Geography, McGill University, Burnside Hall, 805

Sherbrooke St W, Montreal, QC H3A 0B9, Canada

Full list of author information is available at the end of the article
}

informal social control over deviant behaviors and by means of collective actions on the part of residents advocating for the best interests of the community (ex: protests to dispose of physical hazards or to avoid cuts to community services) [3].

Collective efficacy has been associated with many health benefits at the neighborhood level such as lower rates of cardiovascular disease [4], obesity [5], sexually transmitted diseases [6], mental health outcomes [7], and all-cause mortality, [4] as well as positive perceptions of self-rated health [8]. High neighborhood collective efficacy has also been associated with decreased risky sexual behavior among youth [9] and has been shown to enhance the protective effect of family attachment and support on youth's suicidal behaviors [10]. Neighborhoods with high 
levels of collective efficacy are also more likely to solicit internal and external resources to address neighborhood sources of violence, disorder and neighborhood physical hazards [8]. Given the benefits of collective efficacy to a community, gaining an understanding of why some communities have greater collective efficacy than others is important from a public health perspective. To this end, researchers have attempted to understand the neighborhood characteristics and processes that could influence collective efficacy such as built environment design [11], neighborhood attachment [12], poverty [13], and safety [13].

The pathways linking aspects of the neighborhood social and physical environment to collective efficacy can be explained by the existence of a dynamic relationship existing between humans, and their physical and social environments. Although, individuals play an important role in shaping the environment, aspects of the physical and social environment may also in turn contribute to individuals' social and health outcomes [11]. It follows that characteristics of neighborhood built and social environments may explain the unequal distribution of collective efficacy across communities.

Gentrification is a neighborhood process that may contribute to the disruption or development of neighborhood collective efficacy, as gentrification is characterized by a rapid change in the social status and economic characteristics of a neighborhood as compared to the rest of the city [14]. It can be understood as an in-migration of higher-socioeconomic status individuals into neighborhoods of lower socioeconomic status [14-16] resulting in investments in the built environment [17], subsequent increases in property values and rents $[14,18]$ and is generally characterized by an upward transition in status, class, and income of neighborhood residents [18]. In some instances, gentrification may also be the result of real estate or urban developments that result in increasing land values and subsequent displacement of low socioeconomic status individuals [19]. Perspectives on how gentrification could influence collective efficacy are conflicting. At one end, theories of social mix such as Wilson 1987s social isolation thesis [20] suggest that gentrification will improve neighborhood collective efficacy, as incoming high socioeconomic status residents will encourage the propagation of values such as maintaining properties [21], have increased political influence to facilitate the demand for high quality resources, [2125 ] and encourage the creation of community initiatives such as "neighborhood watches" or "citizen patrols" [21]. Conversely, a significant body of literature has revealed that gentrification is negatively associated with the two components of collective efficacy, i.e., social cohesion and informal social control. This work argues that gentrification policies negatively affect vulnerable populations and alter the original social fabric of the neighborhood, promoting social polarization, social segregation and displacement [26-31]. These processes will in turn negatively affect social cohesion and informal social control [30, 32-34], thereby decreasing the likelihood that a community will engage in collective action [25, 28, 35].

\section{Objective}

To our knowledge no studies have undergone an empirical investigation of the relationship between gentrification and neighborhood collective efficacy as a whole. We use data from the Social and Psychiatric Epidemiology Catchment Area of the South West of Montreal (ZEPSOM) (Caron, Fleury et al. 2012) to (1) examine the relationship between gentrification and perceptions of neighborhood collective efficacy and (2) examine whether the effect of gentrification on perceptions of neighborhood collective efficacy is the same for gentrifiers (individuals moving into gentrifying neighborhoods) and the original inhabitants of the neighborhood.

\section{Methods \\ Sample}

The sample was obtained from wave 1 (year 2006) of the ZEPSOM study, an ongoing longitudinal study, organized by the Canadian Institute of Health Research Team in Social and Psychiatric Epidemiology ${ }^{1}$ (Caron, Fleury et al. 2012). The area under study encompassed four boroughs of Montreal: Saint-Henri/Pointe St-Charles, Lachine/ Dorval, LaSalle, and Verdun. The study aimed to recruit 2400 participants from the study area aged 15-65, with proportional representation with respect to geographical location, population density, and socio-economic status (educational attainment).

Trained interviewers recruited potential participants through a door-to-door campaign. The interviewers contacted the residents who had agreed to participate in the study by phone within a week of recruitment, in order to schedule a face-to-face meeting either at the participant's home or in an office designated for that purpose at the Douglas. However, most interviews were conducted at home. The face-to-face interview was conducted once the consent form was signed and lasted approximately $1.5-3 \mathrm{~h}$.

The final sample of 2433 participants represented approximately 600 participants in each borough: SaintHenri/Pointe St-Charles (612), Lachine/Dorval (603),

\footnotetext{
${ }^{1}$ ECA-MSW is noteworthy for McGill's Community-University Research Alliance Making Megaprojects Work for Communities because it contains the site and environment of the proposed McGill University Health Centre, which is the Alliance's primary research focus.
} 
LaSalle (584) and Verdun (635). The cooperation rate was $48.7 \%$. This is superior to the median rates reported in epidemiological studies of populations conducted post year 2000 (Morton, Cahill and Hartge (2006). The study sample overrepresented women (61.6\%) compared to the reference population (51.7\%). Contrastingly, men under the age of 45 were underrepresented. Table 1 presents sample characteristics before and after weighting the data for sex and age. The mean age was 40.73 [standard deviation $(\mathrm{SD})=14.09$ ] of whom $48 \%$ were men, $38 \%$ were single, $45 \%$ were married or in common law relationship, and $15 \%$ were divorced or separated. With respect to educational attainment, employment and immigration status $72 \%$ had a post-high school diploma, $79 \%$ were employed in the last 12 months, while $25 \%$ were immigrants. French was the primary language spoken by $55 \%$ of the respondents, while $21 \%$ spoke English as their primary language. $82 \%$ of the sample was Caucasian. The average personal income was CAN\$ 33,19 $(\mathrm{SD}=\$ 33,15)$ and the average family income was CAN\$ $59,06(\mathrm{SD}=\$ 49,85)$. Based on criteria from statistics Canada, $33.4 \%$ of the participants were considered to be a low income earner.

\section{Measures}

\section{Perception of neighborhood collective efficacy}

Perception of neighborhood collective efficacy was measured using the Sense of Collective Efficacy Scale [2]. The Collective Efficacy Scale is a summary measure of social cohesion and informal social control, with five questions per component. It uses a 5-point Likert-scale, with questions on social cohesion such as: "Are people around here willing to help their neighbors?" and questions on informal social control such as "Do you think that your neighbors can be counted on to intervene if the fire station closest to their home is threatened with budget cuts?" Collective efficacy is often measured at the neighborhood level $[2,8,36]$. However, perceived collective efficacy can also be conceptualized as a cognitive orientation towards one's environment [37]. Measured individually perceived collective efficacy helps to capture residents' perceptions of cohesiveness and common goals [37] and can allow us to disentangle the effect of gentrification on individuals' perceptions of context. Specifically, in this paper examining perceptions of collective efficacy at the individual level was necessary so that we could meet our second objective. This objective was to explore how the perceptions of neighborhood collective efficacy of gentrifiers might differentiate from the perceptions of neighborhood collective efficacy of individuals that had originally inhabited gentrifying neighborhoods before the beginning of the gentrification process.
Table 1 Socio-demographic characteristics of the sample

\begin{tabular}{|c|c|c|}
\hline & $\begin{array}{l}\text { Unweighted total } \\
(n=2433)\end{array}$ & $\begin{array}{l}\text { Weighted total }^{\mathrm{a}} \\
(\mathrm{n}=2432.37)\end{array}$ \\
\hline \multicolumn{3}{|l|}{ Gender (\%) } \\
\hline Female & 61.78 & 51.71 \\
\hline Male & 38.22 & 48.29 \\
\hline Age (mean, SD) & $41.39,13.34$ & $40.73,14.09$ \\
\hline \multicolumn{3}{|l|}{ Age $(\%)$} \\
\hline $15-24$ & 12.00 & 16.12 \\
\hline $25-34$ & 21.58 & 20.66 \\
\hline $35-44$ & 23.59 & 20.84 \\
\hline $45-54$ & 22.44 & 20.92 \\
\hline $55+$ & 20.39 & 21.46 \\
\hline \multicolumn{3}{|l|}{ Marital status (\%) } \\
\hline Single & 36.48 & 37.95 \\
\hline Married & 29.81 & 29.37 \\
\hline Separated & 3.05 & 2.82 \\
\hline Common-law & 15.81 & 15.86 \\
\hline Divorced & 13.13 & 12.39 \\
\hline Widowed & 1.73 & 1.61 \\
\hline \multicolumn{3}{|l|}{ Education (\%) } \\
\hline Less high school & 15.30 & 15.99 \\
\hline High school & 11.51 & 12.13 \\
\hline Post-high school & 73.19 & 71.88 \\
\hline \multicolumn{3}{|l|}{ Immigrant (\%) } \\
\hline No & 75.02 & 75.14 \\
\hline Yes & 24.98 & 24.86 \\
\hline \multicolumn{3}{|l|}{ Primary language (\%) } \\
\hline English & 21.90 & 20.59 \\
\hline French & 54.25 & 55.36 \\
\hline English + French & 6.59 & 6.56 \\
\hline Neither English nor French & 17.25 & 17.50 \\
\hline \multicolumn{3}{|l|}{ Caucasian (\%) } \\
\hline No & 18.69 & 18.46 \\
\hline Yes & 81.31 & 81.54 \\
\hline \multicolumn{3}{|c|}{ Dwelling owned by a household member (\%) } \\
\hline No & 61.47 & 61.15 \\
\hline Yes & 38.53 & 38.85 \\
\hline \multicolumn{3}{|c|}{ Held a job in the past 12 months (\%) } \\
\hline No & 22.60 & 21.41 \\
\hline Yes & 77.40 & 78.59 \\
\hline Household size (mean, SD) & $2.50,1.39$ & $2.49,1.36$ \\
\hline Household income (mean, SD) & $\$ 57,68, \$ 49,72$ & $\$ 59,06, \$ 49,85$ \\
\hline Personal income (mean, SD) & $\$ 32,53, \$ 31,20$ & $\$ 33,19, \$ 33,15$ \\
\hline
\end{tabular}

a The data was weighted for sex and age

\section{Gentrification}

Our measure of gentrification was developed based on the methodology of Grube-Cavers et al. (2014). Gentrification measures were compiled for each participant's neighborhood using census tracts, obtained from the 
Canadian 1996, and 2006 Census datafiles. Indicators used to identify gentrifying tracts included: median household income, proportion of the population with a bachelor's degree, average rent, proportion of the population with low income, and proportion of the population aged 30-44. $Z$ scores for each measure in 1996 and 2006 were calculated using the Montreal census metropolitan area average and standard deviation. We first identified census tracts that had the potential to undergo gentrification by selecting tracts that had negative $Z$ scores in 1996 for median household income, proportion of the population with a bachelor's degree, and average rent and had a positive $Z$ score for the proportion of population with low income. Census tracts with the potential to undergo gentrification were considered gentrified if the difference between the 2006 and $1996 Z$ scores was positive for all indicators except for the proportion of low income, which needed to be negative. A binary variable was then constructed to differentiate census tracts that underwent gentrification between 1996 and 2006 from those that did not.

We constructed a categorical variable: "type of resident", based on the number of years a person lived in a gentrified or non-gentrified neighborhood with the following categories: mover into a gentrified neighborhood/potential gentrifier (lives in a census tract that had undergone gentrification and moved there in 1996 or later); resident whose neighborhood was gentrified (liveds in a census tract that had undergone gentrification and moved there before 1996); mover into a nongentrified neighborhood (lives in a census tract that did not undergo gentrification and moved there in 1996 or later); and residents whose neighborhood wasn't gentrified (lives in a census tract that did not undergo gentrification and moved there before 1996).

\section{Health outcomes}

Respondents were asked to rate their mental and physical health using a 5-point Likert-scale. We classified the responses into the following categories 'good health', 'fair health' and 'poor health' to create the variables "perceived mental health" and "perceived physical health". Respondents were also asked to rate their satisfaction with life using a 5-point Likert-scale. The responses were classified into the following categories 'satisfied with life', 'neither satisfied nor dissatisfied with life' and 'dissatisfied with life'.

\section{Socio-demographic and neighborhood characteristics}

The survey included questions on individual-level sociodemographic characteristics: sex, level of education, first language, housing tenure (renter vs. owner-occupant household), household income in 2006, and number of years that the participant lived in their place of residence.
Most of these variables were unaltered. However first language was categorized into French versus other. Additionally, the continuous variable household income was positively skewed within the ECA-MSW sample group, therefore the base-10 logarithms of this variable was used for normalization purposes. A 2006 neighborhood poverty score was computed by taking the inverse of the sum of the tract $Z$ scores for median household income, proportion of the population with a bachelor's degree, and average rent and then adding the $\mathrm{Z}$ score for the proportion of the population with low income.

\section{Analysis}

Multilevel linear regression analysis was performed to examine the relationship between gentrification between 1996 and 2006 and perception of neighborhood collective efficacy. In these model individuals (i) were nested within neighborhood census units (j). Equation one represents the null model with an intercept $\beta_{0}$, the random effect for the neighborhood census unit $\mathrm{u}_{0 \mathrm{j}}$, and $\mathrm{e}_{0 \mathrm{i}(\mathrm{j})}$ the random effect for individuals $i$ classified within $j$ neighborhood census units.

$$
\mathrm{y}_{\mathrm{i}(\mathrm{j})}=\beta_{0}+\mathrm{u}_{0 \mathrm{j}}+\mathrm{e}_{0 \mathrm{i}(\mathrm{j})}
$$

The level 2 and the level 1 control variables were then added to the model. At level one (individual level) we included the following: Gender $\beta_{1 \mathrm{oi}(\mathrm{j})}$, age $\beta_{2 \mathrm{oi}(\mathrm{j})}$, first language is not French $\beta_{3 \mathrm{oi}(\mathrm{j})}$, level of education $\beta_{4 \mathrm{oi}(\mathrm{j})}$, housing tenure $\beta_{5 \mathrm{oi}(j)}$, household income in $2006 \beta_{6 \mathrm{oi}(j)}$, number of years lived in place of residence $\beta_{7 \mathrm{oi}(j)}$. At the second level (neighborhood) of the model we included the following: neighborhood poverty in $2006 \beta_{80(j)}$ and gentrification $\beta_{90(j)}$.

$$
\begin{aligned}
y_{i(j k)}= & \beta_{0}+\beta_{1 o i(j)}+\beta_{2 o i(j)}+\beta_{3 o i(j)}+\beta_{4 o i(j)}+\beta_{5 o i(j)} \\
& +\beta_{6 o i(j)}+\beta_{7 o i(j)}+\beta_{8 o j}+\beta_{9 o j}+u_{o j}+e_{o i(j)}
\end{aligned}
$$

In our second model, we performed the same analyses except we replaced the gentrification variable with the variable type of resident. Although collective efficacy was our main dependent variable of interest, we also performed multinomial logistic regressions to see if gentrification was related to health outcomes in our sample. To this end, we conducted some exploratory analyses to examine the relationship between gentrification and life satisfaction, selfperceived physical health, and self-perceived mental health using multinomial logistic regression models. All statistical analyses were conducted using SPSS version 20.

\section{Results}

There were 1264 tracts that had the potential to undergo gentrification in 1996 and 353 of these tracts underwent gentrification between 1996 and 2006. Estimates from Table 2 indicate that women had lower collective efficacy 
Table 2 Multilevel linear regression model of the relationship between gentrification and collective efficacy adjusted for neighborhood and socio-demographic characteristics

\begin{tabular}{|c|c|c|c|}
\hline & $\beta$ & $(95 \% \mathrm{Cl})$ & $P$ value \\
\hline Constant & 29.33 & $(25.50,33.16)$ & 0.00 \\
\hline Age & -0.01 & $(-0.04,0.01)$ & 0.31 \\
\hline \multicolumn{4}{|l|}{ Sex (ref. male) } \\
\hline Female & -1.08 & $(-1.70,-0.46)$ & 0.00 \\
\hline \multicolumn{4}{|l|}{ Language (ref. first language is French) } \\
\hline First language is not French & -1.09 & $(-1.75,-0.43)$ & 0.00 \\
\hline \multicolumn{4}{|l|}{ Education (ref. bachelor's degree) } \\
\hline High school or less & 0.46 & $(-0.40,1.31)$ & 0.30 \\
\hline $\begin{array}{l}\text { Post-secondary education of a lower } \\
\text { level than a bachelor's degree }\end{array}$ & 0.61 & $(-0.13,1.34)$ & 0.11 \\
\hline Neighborhood poverty & 0.09 & $(-0.30,0.47)$ & 0.66 \\
\hline Household income & -0.85 & $(-1.56,-0.14)$ & 0.02 \\
\hline \multicolumn{4}{|l|}{ Tenure (ref. owner) } \\
\hline Renter & 2.62 & $(1.88,3.37)$ & 0.00 \\
\hline Number of years lived in dwelling & -0.03 & $(-0.07,0.02)$ & 0.20 \\
\hline \multicolumn{4}{|l|}{ Gentrification (ref. no) } \\
\hline Yes & 1.54 & $(0.16,2.93)$ & 0.03 \\
\hline \multicolumn{4}{|l|}{ Random effects } \\
\hline Tract variance & 2.43 & $(1.32,4.50)$ & 0.01 \\
\hline
\end{tabular}

Significance level: $P=0.05$

than men $(\beta=-1.08 ; 95 \% \mathrm{CI}-1.70,-0.46$, sig $=0.00)$, those where French was not their first language had lower collective efficacy than francophones $(\beta=-1.09$; $95 \% \mathrm{CI}-1.75,-0.43$, sig $=0.00)$ and renters had higher collective efficacy than homeowners $(\beta=2.62 ; 95 \% \mathrm{CI}$ $1.88,3.37$, sig $=0.00$ ). Household income was negatively associated with collective efficacy $(\beta=-0.85 ; 95 \% \mathrm{CI}$ $-1.56,-0.14$, sig $=0.02$ ), whereas gentrification was significantly positively associated with collective efficacy $(\beta=1.54 ; 95 \%$ CI 0.16, 2.93, sig $=0.03)$.

Estimates from Table 3 indicate that women had lower collective efficacy than men $(\beta=-1.09 ; 95 \% \mathrm{CI}-1.72$, -0.47 , sig $=0.00$ ), those where French was not their first language had lower collective efficacy than francophones $(\beta=-1.10$; 95\% CI $-1.76,-0.44$, sig $=0.00)$. Renters had higher collective efficacy than homeowners $(\beta=2.69 ; 95 \%$ CI $1.96,3.42$, sig $=0.00)$. Household income was significantly negatively associated with collective efficacy $(\beta=-0.86 ; 95 \%$ CI $-1.57,-0.15$, $\operatorname{sig}=0.02)$. Movers into neighborhoods that did not gentrify $(\beta=-1.72 ; 95 \% \mathrm{CI}-3.15,-0.29$, sig $=0.02)$ and original residents of neighborhoods that did not gentrify $(\beta=-1.96$; 95\% CI $-3.54,-0.37$, sig $=0.02)$ had lower collective efficacy than individuals that moved into gentrifying neighborhoods. Although a negative tendency can be observed, the collective efficacy of the original residents of gentrifying neighborhoods $(\beta=-1.25$; $95 \%$ $\mathrm{CI}-3.36,0.85$, sig $=0.24$ ) was not significantly different than the collective efficacy of individuals that moved into gentrifying neighborhoods.

Gentrification was not significantly associated with self-perceived mental or physical health. With respect to life satisfaction, individuals living in gentrifying neighborhood had higher odds or reporting being satisfied with life (OR 1.91; 95\% CI 1.05-3.49, sig $=0.03)$ and higher odds of reporting being neither satisfied nor dissatisfied with life (OR 2.69, 95\% CI 1.41-5.14, sig $=0.00$ ) than reporting being dissatisfied with life.

\section{Discussion}

Studies have indicated that gentrification is linked to food insecurity [38], pre-term birth [39] and lower selfrated health in minorities [41]. According to the Center for Disease Control, gentrification may also limit access to affordable healthy housing, transportation choices, quality schools, bicycle and walking paths, and exercise facilities for vulnerable populations displaced by gentrification [40]. Our results imply that the effects of gentrification may not all be negative. These findings indicate that gentrification is beneficial for individuals' perceptions of neighborhood collective efficacy. Collective efficacy has been shown to be associated with positive health outcomes at the neighborhood level such as lower rates of cardiovascular disease [4], obesity [5], sexually transmitted diseases [6], mental health outcomes, [7] and all-cause mortality [4]. This is contrary to the previous literature indicating that gentrification weakens the components of collective efficacy, social cohesion and informal social control [28, 30, 32-34]. Our results are instead in line with Wilson 1987 social isolation thesis that posits that incoming high income residents will encourage the propagation of values such as maintaining properties [21], have increased political influence to facilitate the demand for high quality resources [21-25] and encourage the creation of community initiatives such as "neighborhood watches" or "citizen patrols" [21]. Consequently, gentrification, through means such as increased social mix, will promote collective efficacy [32, 42].

The neighborhood political and cultural shifts occurring because of gentrification can lead to remaining residents losing their power to advocate for resources [43-45]. This may instigate feelings of resentment towards newcomers, [45] who may be threatened with declining relative income and displacement [22]. Thus, we had hypothesized that gentrification would result in improvements in perceptions of social cohesion and neighborhood solidarity amongst gentrifiers themselves $[22,31]$, while simultaneously reducing these perceptions 
Table 3 Multilevel linear regression model for the relationship between type of resident and collective efficacy adjusted for neighborhood and socio-demographic characteristics

\begin{tabular}{|c|c|c|c|}
\hline & $\beta$ & $95 \% \mathrm{Cl}$ & PValue \\
\hline Constant & 31.09 & $(27.13,35.06)$ & 0.00 \\
\hline Age & -0.02 & $(-0.04,0.01)$ & 0.18 \\
\hline \multicolumn{4}{|l|}{ Sex (ref. male) } \\
\hline Female & -1.09 & $(-1.72,-0.47)$ & 0.00 \\
\hline \multicolumn{4}{|l|}{ Education (ref. Bachelor's degree) } \\
\hline Highschool or less & 0.44 & $(-0.42,1.30)$ & 0.31 \\
\hline $\begin{array}{l}\text { Post-secondary education of a lower } \\
\text { level than a bachelor's degree }\end{array}$ & 0.59 & $(-0.14,1.32)$ & 0.12 \\
\hline Neighborhood poverty & 0.08 & $(-0.30,0.47)$ & 0.67 \\
\hline \multicolumn{4}{|c|}{ Type of resident (ref. Moved into a gentrifying neighborhood) } \\
\hline $\begin{array}{l}\text { Original resident of a gentrifying } \\
\text { neighborhood }\end{array}$ & -1.25 & $(-3.36,0.85)$ & 0.24 \\
\hline $\begin{array}{l}\text { Moved into a neighborhood that did } \\
\text { not gentrify }\end{array}$ & -1.72 & $(-3.15,-0.29)$ & 0.02 \\
\hline $\begin{array}{l}\text { Original resident of a neighborhood } \\
\text { that did not gentrify }\end{array}$ & -1.96 & $(-3.54,-0.37)$ & 0.02 \\
\hline Household income & -0.86 & $(-1.57,-0.15)$ & 0.02 \\
\hline \multicolumn{4}{|c|}{ First language (ref. first language is French) } \\
\hline First language is not French & -1.10 & $(-1.76,-0.44)$ & 0.00 \\
\hline \multicolumn{4}{|l|}{ Tenure (ref. owner) } \\
\hline Renter & 2.69 & $(1.96,3.42)$ & 0.00 \\
\hline \multicolumn{4}{|l|}{ Random effects } \\
\hline Tract variance & 2.44 & $(1.32,4.51)$ & 0.00 \\
\hline
\end{tabular}

Significance level: $P=0.05$

in poorer residents remaining in the neighborhood. In contrast, our results suggest that the perceptions of collective efficacy of long-time residents of gentrified neighborhoods was not significantly different from perceptions of collective efficacy of gentrifiers, although a negative tendency was observed. However, newcomers to gentrifying neighborhoods did have higher perceived collective efficacy than individuals living in neighborhoods that did not gentrify.

We also conducted some exploratory analyses to see if gentrification might be related to health outcomes in our sample. Gentrification was not associated with selfperceived mental or physical health. This contrasts with previous research conducted with the Pennsylvania Household Health Survey that found that gentrification resulted in slightly higher self-rated health [41]. With respect to life-satisfaction, our findings indicated that individuals from gentrifying neighborhoods were more likely to be satisfied with life. We hypothesize that these feelings of life satisfaction could be linked to their positive feelings about the upgrades involved in the revitalization of their gentrified neighborhood.

\section{Strengths and limitations}

These results do not suggest that all types of residents from gentrifying neighborhoods will benefit from gentrification. Gentrification is often associated with the displacement of the original inhabitants of the neighborhood $[15,27,45,46]$ an especially critical issue for renters living in gentrifying neighborhoods, who are more likely to have to make involuntary moves [47]. The crosssectional nature of our study and the long time-period used to measure gentrification suggests that we may not have captured the perceptions of neighborhood collective efficacy of many vulnerable individuals that were displaced by gentrification. Rather, our survey likely captured the perceptions of neighborhood collective efficacy of many of the residents that had the financial resources to resist displacement. We distinguished the effect of gentrification on the collective efficacy of gentrifiers from the effect of gentrification on the collective efficacy of the original residents of gentrifying neighborhoods by creating a variable delineating if individuals had moved to their neighborhood in 1996 or later. However, although we can identify the neighborhoods in which gentrification occurred between 1996 and 2006, we had no way of knowing the exact year that gentrification began in each individual neighborhood. Strengths of this study include that the analyses from this paper were conducted with data from the first wave of a longitudinal cohort study making follow-up longitudinal analyses possible. This study is also the first to our knowledge to empirically test the relationship between gentrification and perceived collective efficacy.

\section{Conclusions}

The positive relationship that was found between gentrification and perceived collective efficacy contradicts the notion that gentrification will necessarily create an environment in which residents are less trusting of their neighbors, and foster less political and social solidarity. This study responds to a gap in the literature by conducting an empirical investigation of the relationship between gentrification and collective efficacy. We suggest that future research explore this relationship in other cities and geographical areas.

\begin{abstract}
Authors' contributions
MSW created the gentrification measures, analyzed and interpreted the data and wrote the manuscript. RW and YK contributed to the creation of gentrification measures, analyses and proof-read the manuscript. JC, LB, and GP proofread the manuscript. GP had also conducted some preliminary analyses linking gentrification to social outcomes. JC is the principal investigator of the ZEPSOM study. All authors read and approved the final manuscript.
\end{abstract}

\section{Author details}

${ }^{1}$ Department of Geography, McGill University, Burnside Hall, 805 Sherbrooke St W, Montreal, QC H3A OB9, Canada. ${ }^{2}$ University of Montreal Hospital Research Centre (CRCHUM), CHUM - Pavilion S 850, St-Denis St., Office, 
Montreal, QC H2X 0A9, Canada. ${ }^{3}$ Department of Social and Preventive Medicine, École de Santé Publique de l'Université de Montréal (ESPUM), 7101, rue du Parc, Montreal H3N 1X9, Canada. ${ }^{4}$ GP Rollo \& Associates, Land Economists, Richmond V7A 3A8, Canada. ${ }^{5}$ School of Urban Planning, McGill University, 815 Sherbrooke St W, Montreal, QC H3A 0C2, Canada. ${ }^{6}$ Douglas Mental Health University Institute, 6875 Boulevard LaSalle, Verdun, QC H4H 1R3, Canada.

\section{Acknowledgements}

MSW holds a doctoral fellowship from the Fonds de Recherche du QuébecFonds de Recherche en santé du Québec (FRSQ). RW holds a post-doctoral fellowship from the Fonds de Recherche du Québec - Société et culture (FRQ-SC). LB holds a Social Science and Humanities Research Council - University Research Alliance (SSHRC-CURA) grant no. 833-2007-1009. YK holds a Canadian Institutes of Health Research Applied Public Health Chair in Urban Interventions and Population Health.

\section{Competing interests}

The authors declare that they have no competing interests.

\section{Availability of data and materials}

The datasets used and analyzed during the current study are available from the Canadian Institute of Health Research Team in Social and Psychiatric Epidemiology on reasonable request.

\section{Ethics approval and consent to participate}

The project was approved by the Douglas Mental Health University Institute Ethics Committee, in accordance with the Canadian Tri-Council Guidelines.

\section{Funding}

Support for this study was granted by the Canadian Institute of Health Research (CTP-79839).

\section{Publisher's Note}

Springer Nature remains neutral with regard to jurisdictional claims in published maps and institutional affiliations.

Received: 20 April 2017 Accepted: 22 June 2017

Published online: 14 July 2017

\section{References}

1. Sampson RJ. Collective efficacy theory: lessons learned and directions for future inquiry. Tak Stock Status Criminol Theory. 2008;15:149.

2. Sampson RJ, Raudenbush SW, Earls F. Neighborhoods and violent crime: a multilevel study of collective efficacy. Science. 1997;277:918-24.

3. Kawachi I, Subramanian SV, Kim D. Social capital and health. Berlin: Springer; 2008.

4. Lochner KA, Kawachi I, Brennan RT, Buka SL. Social capital and neighborhood mortality rates in Chicago. Soc Sci Med. 2003;56:1797-805.

5. Cohen DA, Finch BK, Bower A, Sastry N. Collective efficacy and obesity: the potential influence of social factors on health. Soc Sci Med. 2006;62:769-78.

6. Thomas JC, Torrone EA, Browning CR. Neighborhood factors affecting rates of sexually transmitted diseases in Chicago. J Urban Health. 2010;87:102-12.

7. Xue Y, Leventhal T, Brooks-Gunn J, Earls FJ. Neighborhood residence and mental health problems of 5-to 11-year-olds. Arch Gen Psychiatry. 2005;62:554-63.

8. Browning CR, Cagney KA. Neighborhood structural disadvantage, collective efficacy, and self-rated physical health in an urban setting. J. Health Soc. Behav. 2002;43:383-99.

9. Browning CR, Burrington LA, Leventhal T, Brooks-Gunn J. Neighborhood structural inequality, collective efficacy, and sexual risk behavior among urban youth. J Health Soc Behav. 2008;49:269-85.

10. Maimon D, Browning CR, Brooks-Gunn J. Collective efficacy, family attachment, and urban adolescent suicide attempts. J Health Soc Behav. 2010;51:307-24.
11. Cohen DA, Inagami S, Finch B. The built environment and collective efficacy. Health Place. 2008;14:198-208.

12. Comstock N, Dickinson LM, Marshall JA, Soobader M-J, Turbin MS, Buchenau M, Litt JS. Neighborhood attachment and its correlates: exploring neighborhood conditions, collective efficacy, and gardening. J Environ Psychol. 2010;30:435-42.

13. Duncan TE, Duncan SC, Okut H, Strycker LA, Hix-Small H. A multilevel contextual model of neighborhood collective efficacy. Am J Community Psychol. 2003;32:245-52.

14. Grube-Cavers A, Patterson Z. Urban rapid rail transit and gentrification in Canadian urban centres: a survival analysis approach. Urban Stud. 2014. doi:10.1177/0042098014524287.

15. Freeman L. Displacement or succession? Residential mobility in gentrifying neighborhoods. Urban Aff Rev. 2005;40:463-91.

16. Walks A, Maaranen R. Neighbourhood gentrification and upgrading in Montreal, Toronto and Vancouver. Retrieved April 2008, 29; 2012.

17. Clark E. The order and simplicity of gentrification: a political challenge. In: Gentrification in a global context: the new urban colonialism. Routledge; 2005. pp. 261-269.

18. Atkinson R, Wulff M. Gentrification and displacement: a review of approaches and findings in the literature. In: Submarkets and public sector housing [P], 2009; vol 115, pp. 1-29.

19. Glass R. Aspects of change. The Gentrification Debates: A Reader; 1964.

20. Wilson WJ. The truly disadvantaged. Chicago: University of Chicago Press; 1987.

21. McDonald SC. Does gentrification affect crime rates. Crime \& Just. 1986;8:163.

22. Filion P. The gentrification-social structure dialectic: a toronto case study. Int J Urban Reg Res. 1991;15:553-74.

23. DeSena JN. "What'sa mother to do?" Gentrification, school selection, and the consequences for community cohesion. Am Behav Sci. 2006;50:241-57.

24. Formoso D, Weber RN, Atkins MS. Gentrification and urban children's well-being: tipping the scales from problems to promise. Am J Community Psychol. 2010;46:395-412.

25. Freeman $L$. There goes the hood: views of gentrification from the ground up. Philadelphia: Temple University Press; 2011.

26. Butler T, Robson G. Social capital, gentrification and neighbourhood change in London: a comparison of three south London neighbourhoods. Urban Stud. 2001;38:2145-62.

27. Slater T. Municipally managed gentrification in South Parkdale, Toronto. Can Geogr. 2004;48:303-25.

28. Uitermark J, Duyvendak JW, Kleinhans R. Gentrification as a governmental strategy: social control and social cohesion in Hoogvliet, Rotterdam. Environ Plan A. 2007;39:125.

29. Davidson M. Spoiled mixture: where does state-ledpositive'gentrification end? Urban Stud. 2008;45:2385-405.

30. Lees L. Gentrification and social mixing: towards an inclusive urban renaissance? Urban Stud. 2008:45:2449-70.

31. Davidson M. Love thy neighbour? Social mixing in London's gentrification frontiers. Environ Plan A. 2010:42:524.

32. Lee YY. Gentrification and crime: identification using the 1994 Northridge earthquake in Los Angeles. J Urban Aff. 2010;32:549-77.

33. Bacqué Mh, Fijalkow Y, Launay L, Vermeersch S. Social mix policies in Paris: discourses, policies and social effects. Int J Urban Reg Res. 2011;35:256-73.

34. Smith CM. The influence of gentrification on gang homicides in Chicago neighborhoods, 1994 to 2005. Crime Delinq. 2014;60:569-91.

35. Thompson SK, Bucerius SM, Luguya M. Unintended consequences of neighbourhood restructuring uncertainty, disrupted social networks and increased fear of violent victimization among young adults. Br J Criminol. 2013;53:924-41.

36. Lochner K, Kawachi I, Kennedy BP. Social capital: a guide to its measurement. Health Place. 1999;5:259-70.

37. Nix J, Wolfe SE, Rojek J, Kaminski RJ. Trust in the police: the influence of procedural justice and perceived collective efficacy. Crime Delinq. 2015;61:610-40.

38. Whittle HJ, Palar K, Hufstedler LL, Seligman HK, Frongillo EA, Weiser SD. Food insecurity, chronic illness, and gentrification in the San Francisco Bay Area: an example of structural violence in United States public policy. Soc Sci Med. 2015;143:154-61. 
39. Huynh M, Maroko A. Gentrification and preterm birth in New York City, 2008-2010. J Urban Health. 2014;91:211-20.

40. Control CfD. Health effects of Gentrification; 2013.

41. Gibbons J, Barton MS. The association of minority self-rated health with black versus white gentrification. J Urban Health. 2016;93:909-22.

42. Chaskin RJ, Joseph ML.'positive'gentrification, social control and the 'right to the city' in mixed-income communities: uses and expectations of space and place. Int J Urban Reg Res. 2013;37:480-502.

43. Chernoff M. Social displacement in a renovating neighborhood's commercial district: Atlanta. In: The gentrification debates: a reader. New York: Taylor \& Francis; 2010. p. 295.
44. Fraser JC. Beyond gentrification: mobilizing communities and claiming space. Urban Geogr. 2004;25:437-57.

45. Hyra D. The back-to-the-city movement: neighbourhood redevelopment and processes of political and cultural displacement. Urban Stud. 2014. doi:10.1177/0042098014539403.

46. Newman K, Wyly EK. The right to stay put, revisited: gentrification and resistance to displacement in New York City. Urban Stud. 2006:43:23-57.

47. Martin IW, Beck K. Gentrification, Property Tax Limitation, and Displacement. Urban Aff Rev. 2016. doi:10.1177/1078087416666959.
Submit your next manuscript to BioMed Central and we will help you at every step:

- We accept pre-submission inquiries

- Our selector tool helps you to find the most relevant journal

- We provide round the clock customer support

- Convenient online submission

- Thorough peer review

- Inclusion in PubMed and all major indexing services

- Maximum visibility for your research

Submit your manuscript at www.biomedcentral.com/submit
() Biomed Central 